\title{
RECONCILING THE LIVING LANDSCAPE WITH OUR LIVING CULTURE`
}

\author{
Brian Goodey*
}

\begin{abstract}
Conservation townscape ideas and understandings move with generations and innovations (Fallowwell et.al, 2010). As new generations respond to an electronic and globalised world, daily life and public policy seem to respond to events, often leaving the settings to take care of themselves. Often the only environmental response is to ensure basic facilities, or to enhance for the benefit of an essentially tourist market. The historic context of many decisions is having a hard time. One is not to compliment oneself on a job well done, nor does society often understand what one is doing. It is seen as a desirable commodity for those who can afford it, a significant factor in Western planning perhaps, but modest when faced with community protest for basic facilities. It is somewhat of a luxury, and it is treated as such.

Culturally and politically one relies on the shared meanings and understandings behind current public life, and therefore on the landscape, both the green landscape and built settings provide a mental context for one's actions. So when London is mentioned a particular image of London comes to mind. That image might be a complex overlay of television images, personal visits, narrations from relatives, or political events. They all come together and everyone has a different image. The next decision about London, will be based on a combination of those images.
\end{abstract}

The big question remains as to how, and to what degree, should these contexts be conserved, maintained and promoted in contemporary cultural life? The argument in this paper is around the fact that these past remnants are not just for the package holiday visitor, but their presentation serves as an essential, visible text to remind citizens of the origin of their current beliefs and aspirations. They are markers of where one has been.
Urban squares, buildings, and routes, and the arrangement of rural land provide the textbook for what is to be retained, retrieved or rejected in the future, they are part of personal encyclopedias. They are often more eloquent and universal in their language than the modern polemic, and ways must be found for re-incorporating them into the thought process of a contemporary population. It is 'thinking differently' by the current generations, as well as the generations that are to follow, that is both interesting as well as very disturbing. Electronic media should be used to learn about place, but it also means that a lot of older ideas need to be re-evaluated with a big task at hand for teachers. The challenge for those who choose to conserve and understand such places is how to integrate them with the current ways of knowing.

Keywords: Heritage, Urban Meanings, Culture, Landscape

\section{PERSONAL HERITAGE}

Everybody has a personal heritage. Somebody who has never been to school has a personal heritage, and so does a professor with many degrees. One is not better than the other, as they are based on human experiences and not on exams. A rose garden in front of a house can be part of some ones personal heritage and have many memories associated to it.

Buildings are not the only places to start with this idea of townscape heritage, it is perhaps the stories that are most important. This can be demonstrated by a small example. An American colleague, Henry Sanoff, asked a group of his students to conduct surveys in a small town in North Carolina with regard to how that town should spend a certain sum of money that was available for building conservation. They identified two potential buildings to be conserved. One was an historic courthouse, which naturally had all sorts of

- This paper was presented by Prof. Brian Goodey as the keynote speech in the $6^{\text {th }}$ Seminar of Urban and Regional Planning, organized by Department of Architecture and Planning, NED University of Engineering and Technology in 2011, and has been revised and updated for this publication.

* Prof. Emeritus Brain Goodey, Department of Urban Planning, Oxford Brookes University, UK, Email correspondence: bgoodey@brookes.ac.uk 
official understandings around it, the other building was a 1930's Roosevelt period high school. The town was asked which of the two buildings they wanted to conserve. Quite naturally, it was the high school, not a particularly brilliant piece of architecture, but everybody from the town had been there; almost everybody had had a positive experience and saw its significance in the lives of their children. The high school was part of a living community, the courthouse, which the experts on architectural conservation might have gone for, unfortunately housed the town jail, the court, the sheriff's department, and the tax department. Four negative strikes against that building. This had nothing really to do with the architecture, but a lot to do with how people experienced that place.

Similarly, a bus stop near an all boys school, where the boys got to meet girls and have a chit chat, had many memories attached to it. If it were replaced by a housing scheme memories would have been lost.

\section{HERITAGE OF URBAN MEANINGS}

Everyone has a particular baggage of personal heritage. A grandmother's house in the town will have a special meaning especially it if is a completely unexceptional house (Figure 1) in terms of its architectureal significance, with no special cause for interest other than its name such as called Tekrit, after a grandfather who was killed in Tekrit in Iraq in the First World War. This house might be the only house in England that has an Iraqi town name on it. But it is still there, which is more than can be said for the grave in Iraq.

The development of designations for officially identified quarters, zones, or other areas has often served to remove the complexity of urban meanings, superimposing an academic or official convenience. A paper on Manchester (While and Short, 2011: 5) notes that 'the cultural built heritage for most localities is intensely hybrid... in that, the inherited built environment is always the product of successive waves of development, redevelopment, modification, and change. In other words, some places (or parts of those places) may be more coherent than others in terms of aspects of extant cultural built heritage, but even places that are recognized (or branded) as historic are invariably assemblages of urban interventions over time.... local planning frameworks, and especially place marketing strategies, tend to present 'heritage' in terms of reasonably coherent spatial identities.'

This aspect of heritage has led to a moulding of certain areas for certain periods, forgetting their diversities and that they always change. There are always new interventions, and we have to learn to expect and to accept these.

While and Short (2011), were writing about Manchester, a city not internationally renowned for its heritage. Subject to bombing by the IRA, it had to rebuild large areas, and certain modern movement buildings were then accepted as part of the heritage prior to that destruction.

In the past few years there has been an engagement with a longitudinal study of townscape initiatives in Britain (Shipley and Reeve, 2010, Goodey et.al., 2004 and 2007). These were Heritage Lottery Fund designations, and the longest succession of projects have been run on a group of towns, a sample of sixteen schemes from ninety initiated over thirteen years.

The key question then becomes - is all really worth it? Conservation, local education, and other social and economic factors, work together to add value to a place in the long term. This is quite difficult information to get at and the very parameters that make the research effective tend to obliterate the more personal and idiosyncratic of memories.

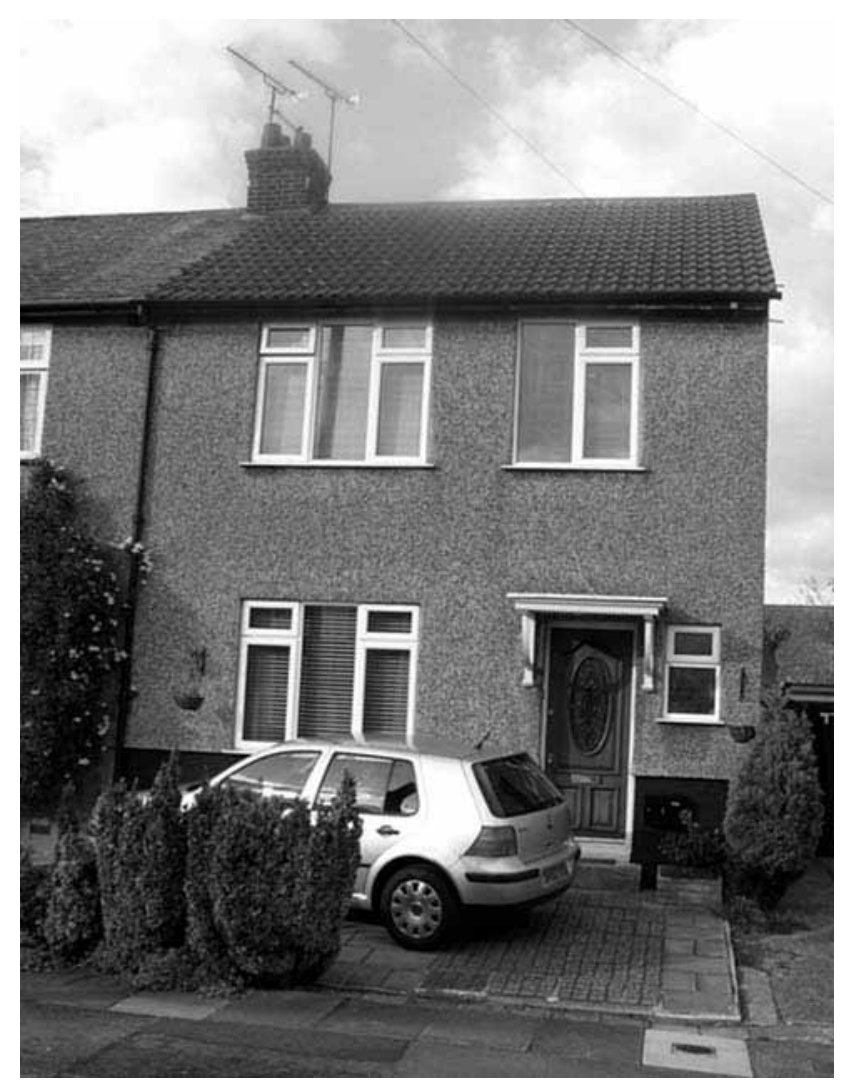

Figure-1: 'Tekrit' my grandmothers's house in Chelmsford, U. K. 
For instance if one can study the diversity of buildings and their existing urban meanings one should start with an anomalous conserved structure, a bridge in Mostar, Bosnia that links two communities which has been rebuilt by the Turkish government after wartime damage (Goodey and Desimpelaer, 2003). Bridges are of much more interest to the community at large than are buildings, as bridges always link things, and in this case communities (Figure 2). In Britain peoples' favorite building are towers or bridges. These are feats of engineering and may be more attractive than buildings because one can see their workings and purpose at a glance. Buildings almost always have an inside that needs to be explored, which most people do not have the time to do, as they just pass by them.

The Athens Acropolis (Figure 3) for example, is a global phenomenon. One of the enduring features of the townscape is the towering hilltop monument. In Karachi too, there are small and large monuments that are turning points in the traffic system. They are markers, continuing evidence of Lynch's pioneer urban analysis (Lynch, 1984).

It is appropriate to consider the settings rather than the buildings because, for most people, it is the space between the buildings that they use rather than the buildings themselves as they traverse and experience the city (Wood,1995). For example, when one goes to a concert, a political rally, or any other open-air event, one doesn't normally stand there looking at the buildings, but participates in the activity that is going on in the contained space. It is the setting that becomes the primary element of that space. As long as the setting is familiar, and one knows that one can be there, it is what happens up front that is more important than the backdrop.

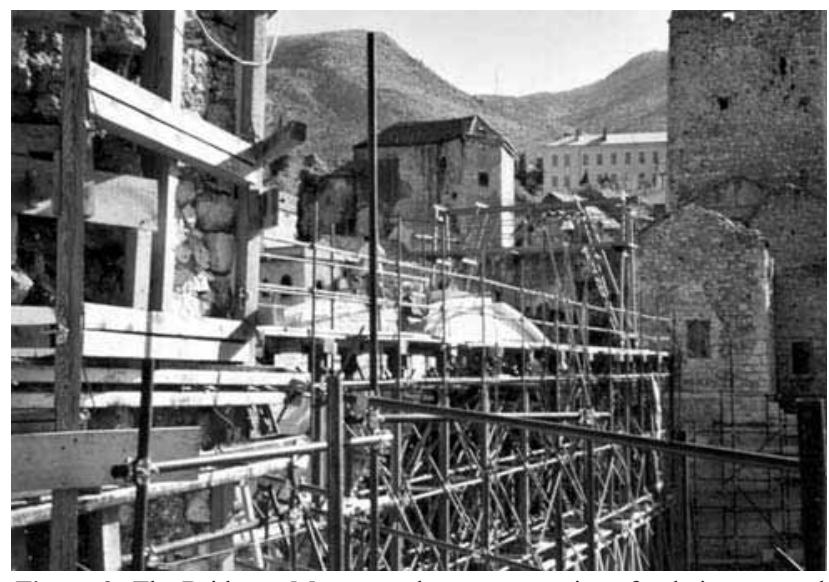

Figure-2: The Bridge at Mostar, under reconsturction after being severed during the Bosnian conflict.
In some spaces the building are hardly a concern, as in the open-air market in Malaysia (Figure 4). It is essentially the activity that is the conservable object. The activity needs to be maintained in order to give vitality to the market space.

Corners within the cityscape are important as well. They act as turning points, modest intrusions in the eye, but landmarks for navigability of a city, allowing one to steer the way through. In some countries, including England, a small street corner could vanish overnight, without anybody thinking how it was used in navigation, or what significance it held for the townsfolk.

Steps are also a primary cityscape feature, they are available to anybody. Sometimes, the building might not be as important a feature of the urban setting as are the steps that lead up to it. This is especially the case with large, monumental stairways that open up to public squares.

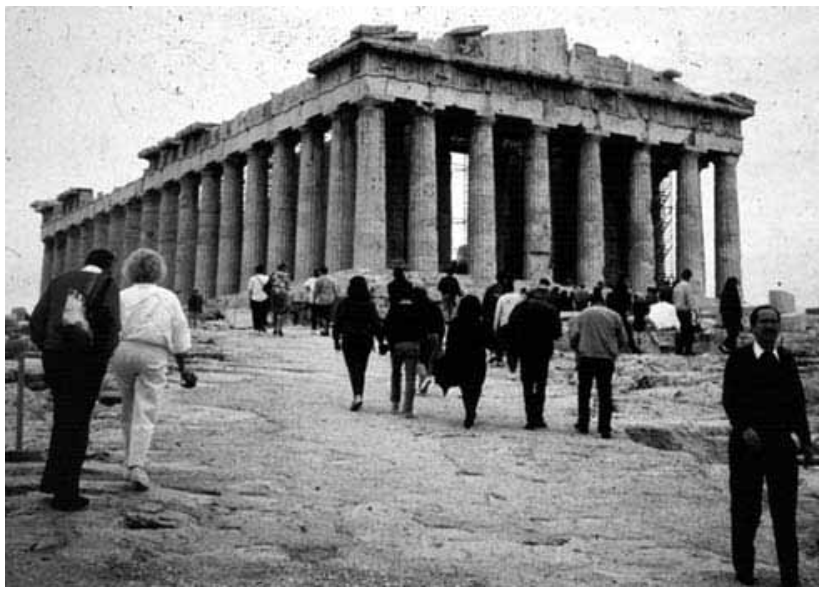

Figure-3: 1970's tourist view of the ill-informed visit to the Acropolis, Athens.

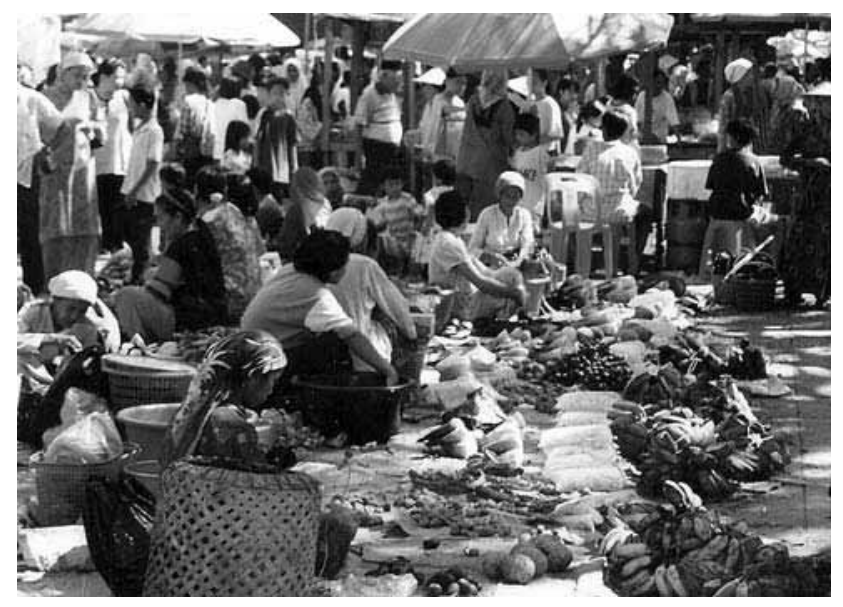

Figure-4: Local market in Malaysia. 
Thus, thinking of public spaces around the building and their conservation is as important as conserving a building or sometimes more important for many people than the buildings themselves.

\section{FADED MEANINGS}

People today say things are changing very rapidly, much faster than people can accommodate. Those of a younger generation might, perhaps, say they want things to change even faster. This is because of age, and how much one can carry in their mind. One has to realize that one carries a vast filing cabinet in one's head, which is continually bursting with papers falling out. Some people still have space left in the filing cabinets, so they want more experience, more change, and more learning.

Culturally one might empty out the heads. At times radical changes are made to the way the built environment is used. Lynch's (1961) work emphasizes on local landmarks, but a number of meanings are in decline. Going around Karachi, one can see how the Colonial-era meanings are fading fast as generations who were alive during that period pass. But, perhaps more recent meanings are fading as well, especially functional meanings.

If one is asked in a street in Oxford the way to a particular place, one would probably direct with reference to a church on the street corner, or a local pub. Today attendance at churches is declining so rapidly that in England, and about a dozen other European countries, within the next generation, there is likely to a massive crisis as to the funding and upkeep of churches. Locally the established parish church retains the community values, much in the same way that a mosque does. There is real tension, as people would like to retain the church spire, but they are really unwilling to consider the process of thinking why it is there. Pubs, public houses, were the social focus of British urban life down to the 1950's and 1960's. But because of a range of legislation in terms of smoking (pubs are primarily non-smoking areas) and alcohol prices (more people now drink at home), pubs are in rapid decline. This is a real problem - if two of the main landmark features that are used to navigate towns are under threat, what is the new language of navigation?

Cathedrals will always stay, but imagine the cost of maintaining a huge medieval cathedral by a religion that is not well-financed. One solution might be to move churches to museums - small Welsh church, originally located in a hilly valley, was moved into a museum in Southern Wales.
Many more people will be able to see it but one cannot possibly move around all the churches that are becoming obsolete or falling into neglect.

It is just not about fading meanings, but lost meanings. For example, a church in a London commuter village contains a 1000 AD, pre-Norman, font where a few children are still baptized. If any of the residents have looked at it in close detail, unique design that represents Noah and his boat will be seen. It is an amazingly modern piece of design (Figure 5) but unless one has read quite a detailed guidebook on it, one will not be able to fully appreciate its beauty and its meaning. A church nearby has a contemporary report by a clergyman on the effects of the Plague of the $14^{\text {th }}$ century written on its wall. Most of the village died in the Plague, and he wanted to report that. Churches contain a fantastic amount of physically accessible history, and yet, even if one has the financial means to conserve them, there is a massive gap between their physical and cultural accessibility.

Possibly, as Conn (2010: 163) notes, the gap is between the past and present cultures:

'Museums, archives, cemeteries. festivals, anniversaries, treaties, depositions, monuments, sanctuaries, fraternal order - these are the boundary stones of another age, illusions of eternity. It is the nostalgic dimension of these devotional institutions that make them seem beleaguered and cold they mark the rituals of a society without ritual; integral particularities in a society that levels particularity; signs of distinction and of group membership in a society that tends to recognize individuals only as identical and equal.'

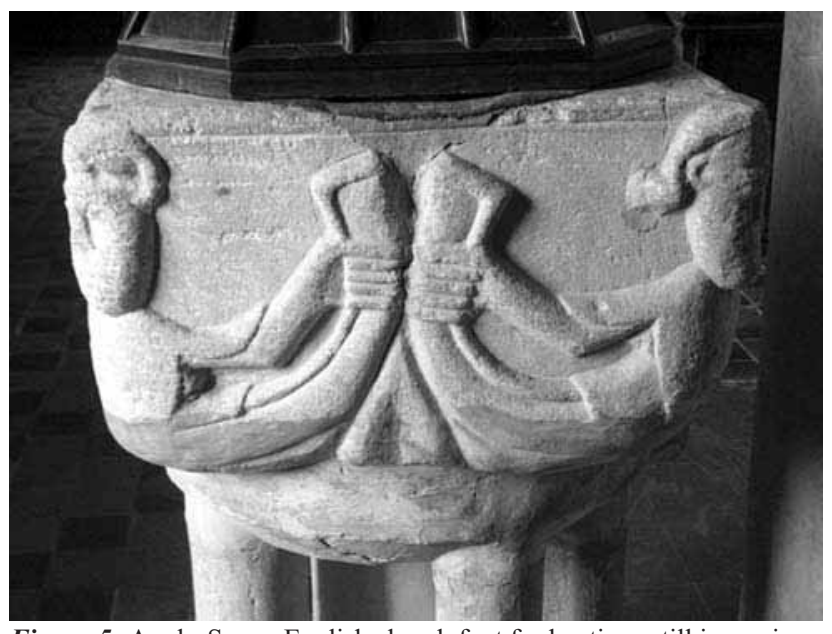

Figure-5: Anglo-Saxon English church font for baptism, still in use in Hertfordshire. The simple marine images are both ancient and modern. 


\section{ATTACHMENT TO THE GRAPHIC}

When it comes to cuisine, very different local styles of food have also been replaced. For there is also an accessible cultural heritage of food. Foods are also changing very rapidly. For instance 'Pie and Mash' shop (Figure 6) in London now has very few shops remaining that actually sell eels, though it used to be the standard working class fare for East London. Pubs are diminishing as well, and their names no longer resonate with a declining local, but increasing tourist clientele. For example, a pub named "The Essex Serpent" in Covent Garden (Figure 7) is no longer visited by workers from the closed fruit market. Its name does not present the same meaning or charm to its new audience. The Essex Serpent was a $15^{\text {th }}$ century myth that most users of the pub today would not have a clue about. Some pubs that are being reestablished are actually using history. A pub in Manchester has depicted on its nameplate former modes of transportation, such as a horse drawn carriage, a doubledecker bus, and a tram (Figure 8).

There is an immense teaching and education task that needs to be undertaken, together as students and teachers, have got to do it for the benefit of the community. One has to move in a way in which people understand cities (Goodey, 2006). The understanding of townscape varies from country to country. Townscape, in China for instance specifically, is not the buildings in general, but the neon signs. One navigates using neon signs, and the character of the street is made up by the typical colors of its neon signs. It is very much the façade, but the building façade is essentially eliminated. One has to think seriously about what a whole succession of experiences with regard to mass media, movies,

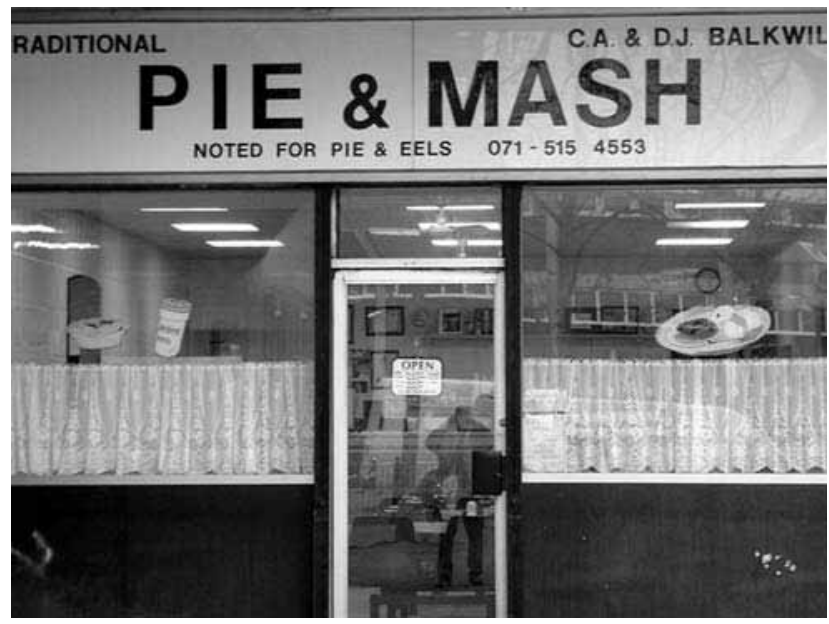

Figure-6: Pie ad Mash shop in modern shopping centre, Poplar, London; a relic of popular working class fast foods.

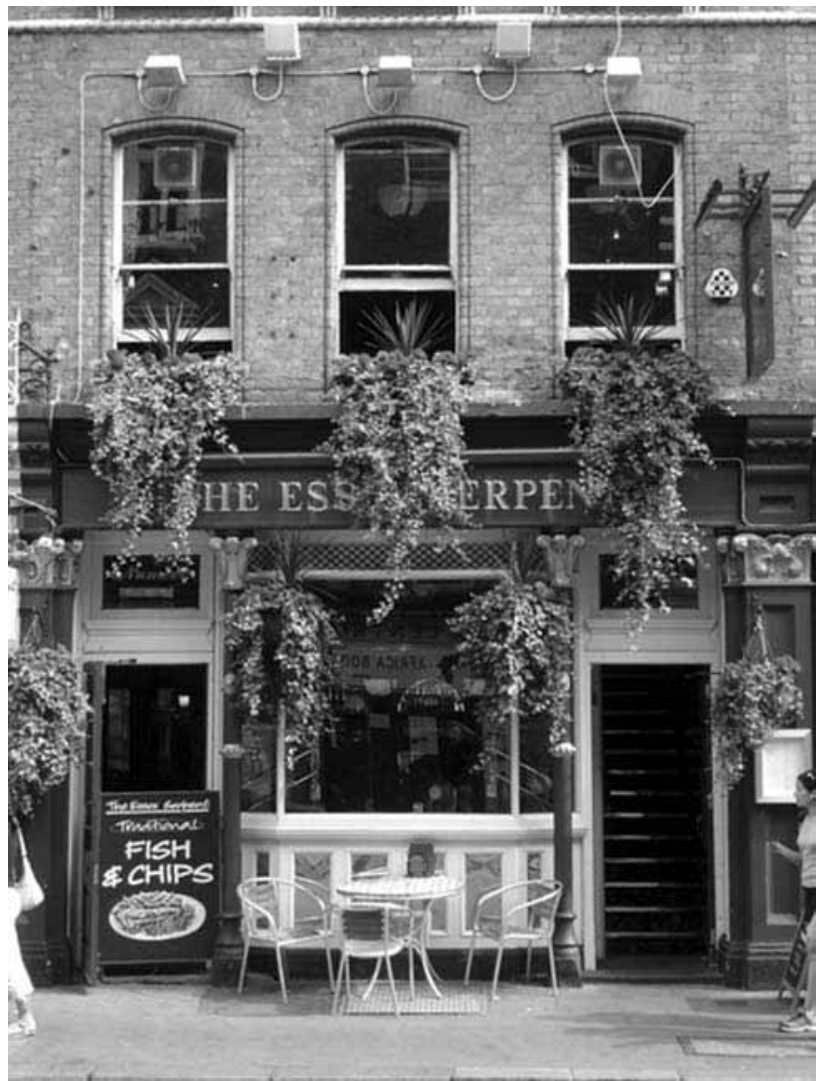

Figure-7: The 'Essex Serpent' in Garden.

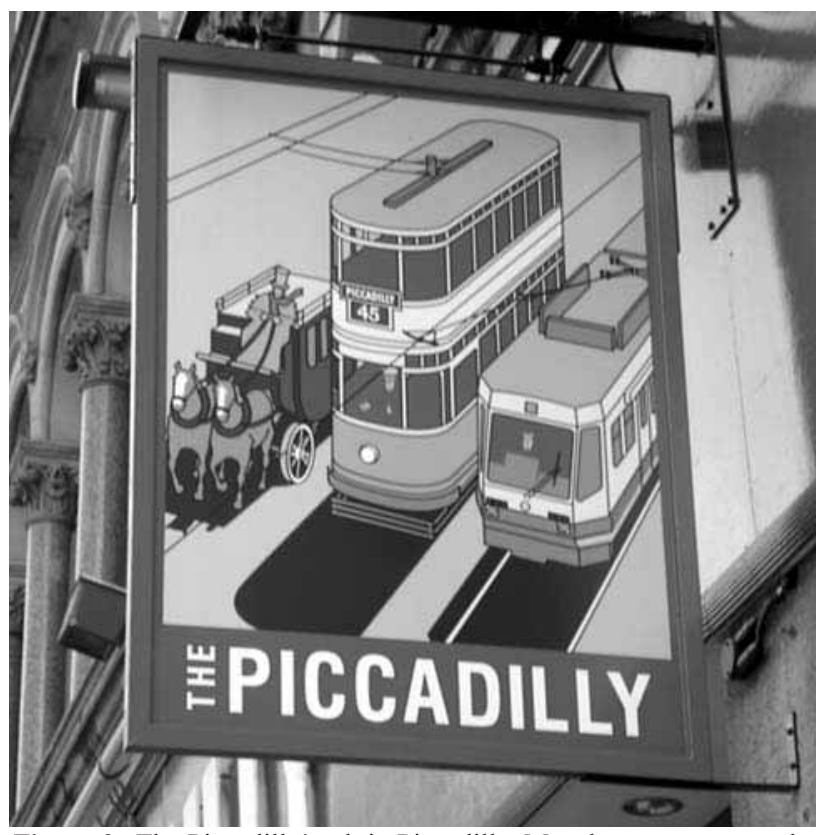

Figure-8: The Piccadilly' pub in Piccadilly, Manchester: recreates the history of $20^{\text {th }}$ century transport. 
television, the mobile phone, and the computer, have done to the way one learns about and responds to an urban place (Zukin,2010). The role of media in shaping places becomes important. No longer does one learn from long, dusty, books which explain the details of architecture, but from images repeated in a variety of places. It is very selective. The townscape of graphic messages, of visible waves of information, was identified by American architect Venturi, et. al. (1977) in his student study visit that generated "Learning from Las Vegas". In the book Venturi drew on the desert gambling centre's strip to identify the townscape of billboards and signs.

Architects and urban designers are not amused but the age has arrived where most people are tapping into the way Venturi described urban learning. People tend to be moving by vehicles rather than on foot, and they look for the large messages, because large and simply framed messages are continually repeated in the media. So it is time to have a look at Venturi, and at what Venturi's critics have written about him. People have to accept that different townscapes include different forms of signage, graphic displays and monuments.

There have almost always been graphics in the town. Street names are very interesting - noticeable graphic feature is town signs, these are becoming increasingly common in Britain. Town signs announce the uniqueness of place, in the United States, one can find murals at significant public spaces within towns that summarize the local hitory for the townsfolk (Figure 9). This is done in the hope that people who haven't read the history in books would pick it up from such murals on large public walls. Another aspect of public

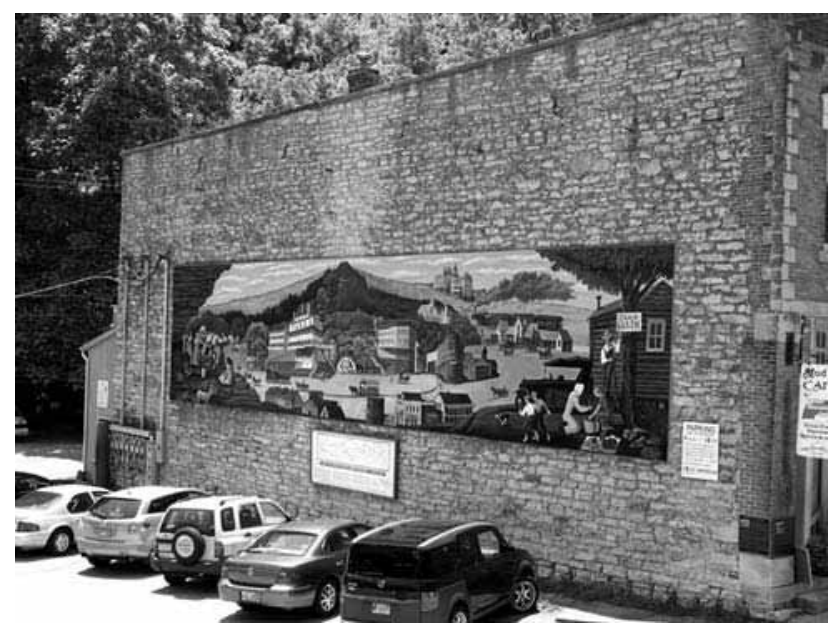

Figure-9: Contemporary wall painting presenting the history of a town in Arkansas, U. S. A. graphics, is the occasional graffiti artist, whose job is to promote and provoke people. But the question is, is graffiti vandalism? It is certainly not in Britain now, especially with the significance of the artist Banksy (Figure 10). The new language of graffiti, street art, and art for the environment is becoming very much part of the townscape. One ought to consider how and what is added to it, how it is conserved, and how it helps make places. Some cultures are very useful in that regard. Mexico has used the mural as a basic teaching and educational device since the 1930's, to pave the way for spreading urban awareness. The French are more subtle in this regard, a blank wall in Montpellier was painted over as a mural depicting a building façade, with arches, and windows that reflected figures and images of the townscape

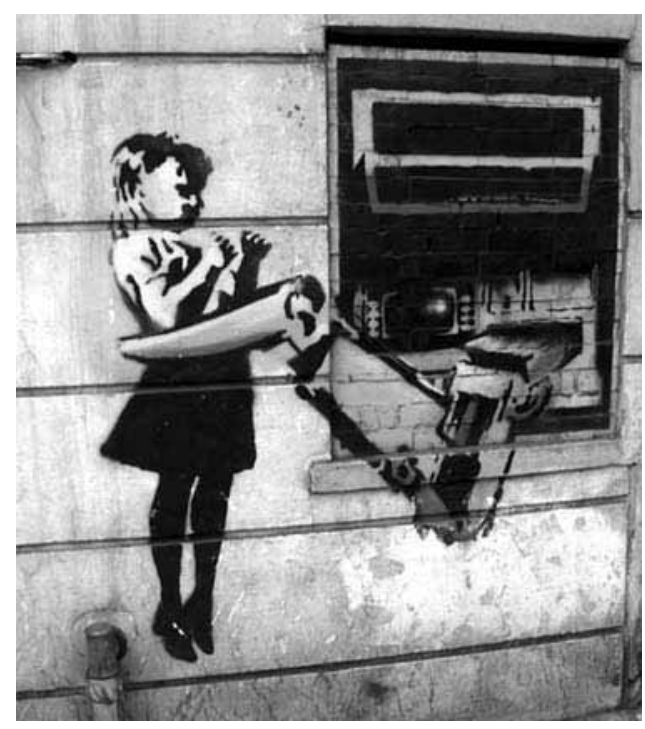

Figure-10: Graffiti artist 'Banksy's' critique of the banking system, painted in Exmouth, Clerkenwell, North London.

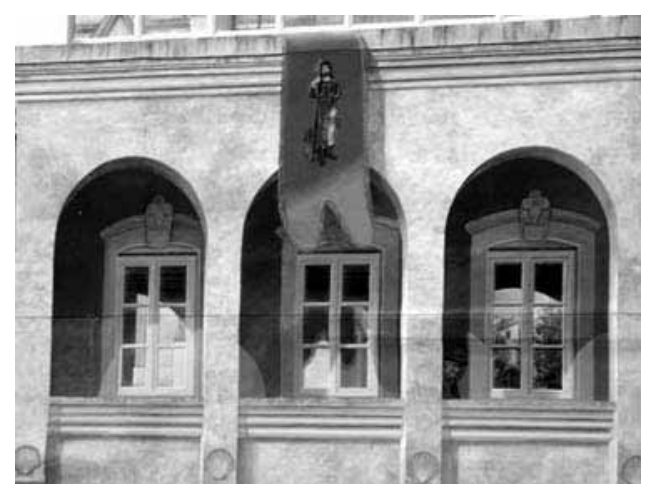

Figure-11: Public art used to animate a restored blank façade, Montpellier France. 
(Figure 11). Similarly, a mural on a large blank wall in California, called the "Arizona Coast" (Figure12), depicted what would happen in case a large earthquake gobbled up the whole of California. Now, one could pass on the same message through newspaper headlines, one can do it with pundits on television, but if one sees a large mural daily that depicted this scene graphically, it would start giving thoughts about where one stands, or shake.

So, public art can be a very useful communicative tool, and has also been used symbolically in many cultures to maintain and support existing political systems. For instance, there are still statues of Lenin in Ukraine. In Britain, the cultural heroes are looked upon and needless to say they are not politicians, but usually footballers. It is interesting to see how football is emerging in the streets as more than merely a game, in the form of celebrity statues and team messages posted around towns (Figure 13).

The Angel of the North, a tall landscape sculpture in Newcastle, has made its place on the list of the top ten most known buildings in Britain in just ten years. It is large, it demonstrates the vitality of Northeast England, it uses modern engineering materials, and it makes a statement about the city today.

The whole array of urban graphics and official, and informal, public art help differentiate place and assist memory and navigation. They are often more accessible than the professionally and fine art defined building subjects of conservation effort.

\section{EVENTS}

Events in the city are important too. It seems that if one can manage to involve the local community in commemorating itself, or help in creating new memories, or manage to draw people into public spaces, one achieves a key aspect of urban design. Events can often aggravate or accelerate hidden meanings in society and can relieve tension from a society. In England, there is Morris Dancing - men in white trousers and funny hats dancing around the streets with sticks and bell, or with more threatening outfits (Figure 14). This has quite deep undertones of fear and superstition. The Day of the Dead in Mexico commemorates deceased souls and spirits. The whole country visits graveyards, thinks of the family, and pays homage to the dead. But in essence, it relives the tension of fear, concern, and regret, and is marked as a marvelously jubilant day. Townscapes, this way, serve as places or settings for events - markets remain some of the most free of such place makers (Calabi, 2004).

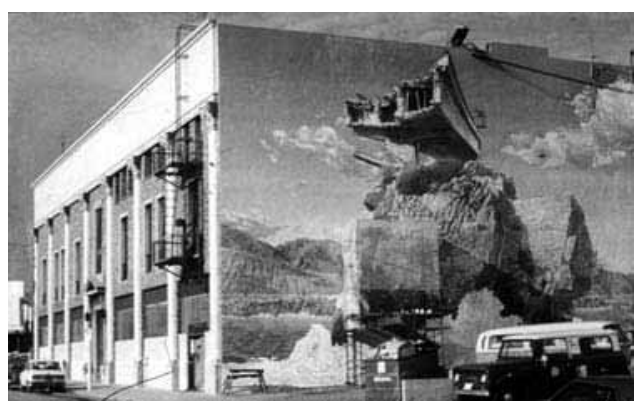

Figure-12: 1960's Los Angeles end of block painting showing the 'Arizona Coast' with the implication that with an earthquake the whole of California could be submerged.

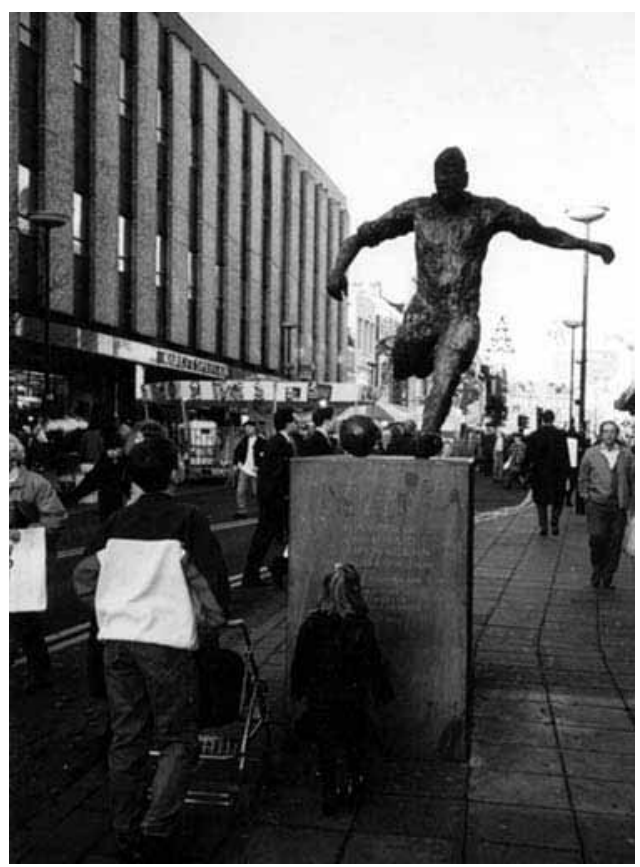

Figure-13: Statue of Nat Lofthouse, much respected player with Newcastle United. Located in central Newcastle the statue is dressed in scarves with a Newcastle win.

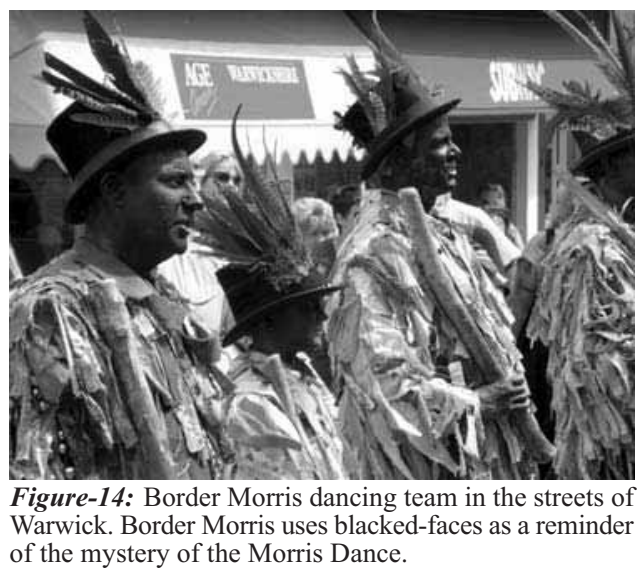


Sometimes, events take over these places completely, sometimes moving streetscape with a rich layer of highly decorated vehicles with scenes and dreams of wished-for places (Van Oppen, 1992)

\section{WHAT GETS SAVED AND WHY?}

Originally, conservation was developed by elites who sought to save the evidence of their dominance in a society. Greiff (1974) notes the early importance of the 'Daughters of the American Revolution' in establishing the significance of $18^{\text {th }}$ century buildings in American society - a form of 'ancestor worship.'

But today, what gets saved, and why? Why is it decided to save certain elements or settings? One rule that applies is rarity - when people start saying that there aren't many more of a certain object left around, other people would come forward and try to save one or two for the future, but it does mean that an awful lot would go away in the meanwhile.

Along with rarity comes the fact that something may be very common throughout the country but not in a particular region. So if a region has one or two of that object, it automatically becomes a novelty - a matter of local uniqueness. The third reason is the ability to reconcile with prevailing economic utility of a building or a site - this is extremely important as one has got to go with the flow in many cases. The flow in Karachi certainly talks of new, large buildings. Integrating conservation financially and culturally with the development process is a key achievement. The people who are mainly interested in making money need to be taken into confidence in order to save cultural heritage. It takes a lot of work, but it is one of those areas that really needs to be worked on. What does get saved occasionally are odd buildings which are preserved by developers.

Another way of conserving and getting things saved is that the owner realizes the status that can be achieved by conservation, this is a matter of public education. In many old houses, people are selling off their woodwork and vintage décor as it is more significant to have a modern house without such rustic elements. If, however, a prominent cricketer in Pakistan has an old house that he preserves, or there are photographs in a style magazine of something like that, the status to be achieved by doing the right thing is enhanced. In many cases, that is a process that has nothing to do with conservation as such, but more with public relations, by which one can get people to support conservation attempts. Conservationists have to learn a few more tricks than mere architectural knowledge to save buildings (and there are a lot of tricks to learn).

There are shifts in shared public memory. Events occur that suddenly make places important. When military bases close down, for example, as they are in Britain, they contain the lives of many people. Some might want to retain the physical structure of the base, even if it changes its function, rather than demolish the building completely. As another example, a building in Worcester that was used for selling hops was recently converted to a courtyard market rather than being pulled down.

There are certainly enthusiasts of the modern movement, but many who wish to conserve older buildings are not too interested in conserving modern buildings. A sculpture park in Britain which contained artwork by some of Britain's best known sculptors was recently removed to make space for a new supermarket, as the town needed new shops (Figure 15). This is a case of something that does not get saved because it is not old enough, or does not have the right image. That occurs very often, and one should question why that is happening.

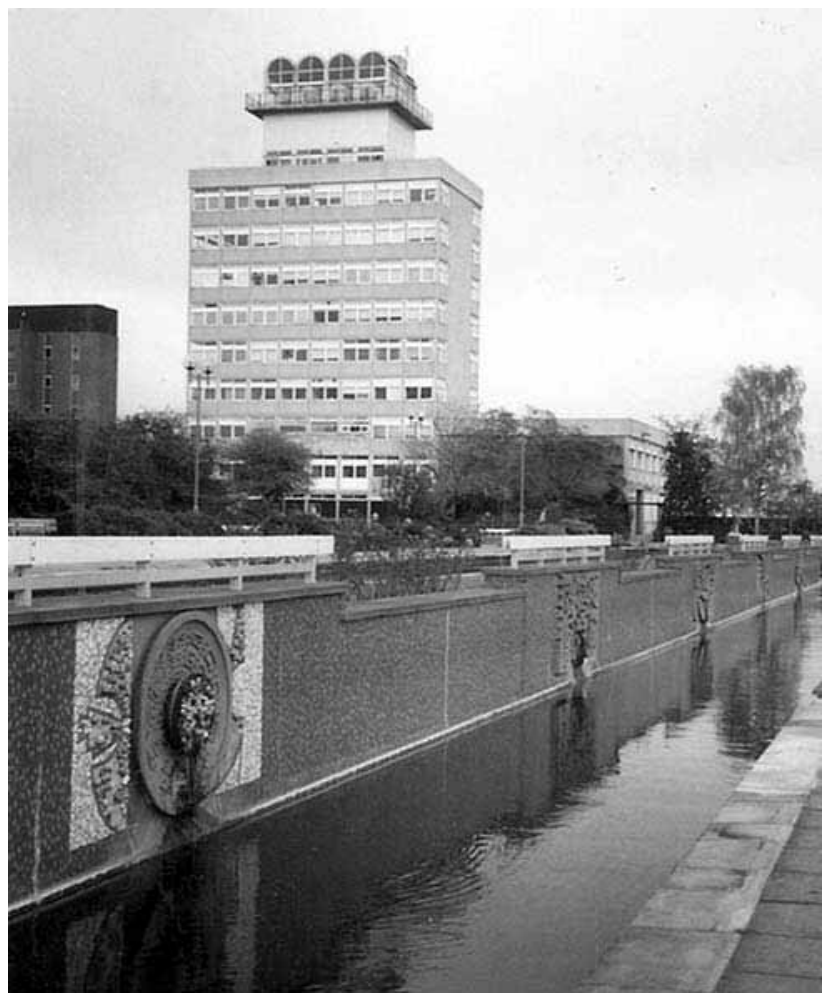

Figure-15: The Water Gardens at Harlow New Town, Essex, prior to demolition for a new shopping centre. Designed by Frederick Gibberd, the Water Gardens included work by Frink and other sculptors the wrong place at the wrong time! 
Rarity, as mentioned before, is also a major feature. For instance pottery kilns in Staffordshire are now being saved. There was a time when they dotted the horizon by the hundreds, (Figure 16) and it was not until a very few of them were left that people started conserving them. In Birmingham in 1968, the whole town was filled with back-to-back houses. Houses that essentially share three walls as it was the cheapest way of building construction during the $19^{\text {th }}$ century. These were in very poor condition, and whole areas within these building compounds were vacant (Figure 17). Only after massive demolition did the charitable National Trust discover a small, city centre group, and now presents them as a tourist remnant of the $19^{\text {th }}$ century.

Ideas about what needs to be conserved keep changing. There was one particular building in Birmingham, a skyscraper office tower, a good landmark, and people knew it very well. There was a plan, since completed, to renew the city's 'Bullring' area, and this building was threatened (Figure 18). However, despite the completion of the new Bullring, it has been retained by Urban Splash Developers for residential use.

Why, one wonders, this sudden change in action? The building received popular support in the newspapers, forcing the developers to conserve rather than demolish the building. Still, it was just like any other modern building - how did it suddenly become loved? One, it was a landmark. Two, a pub at the base level of this building was bombed by the

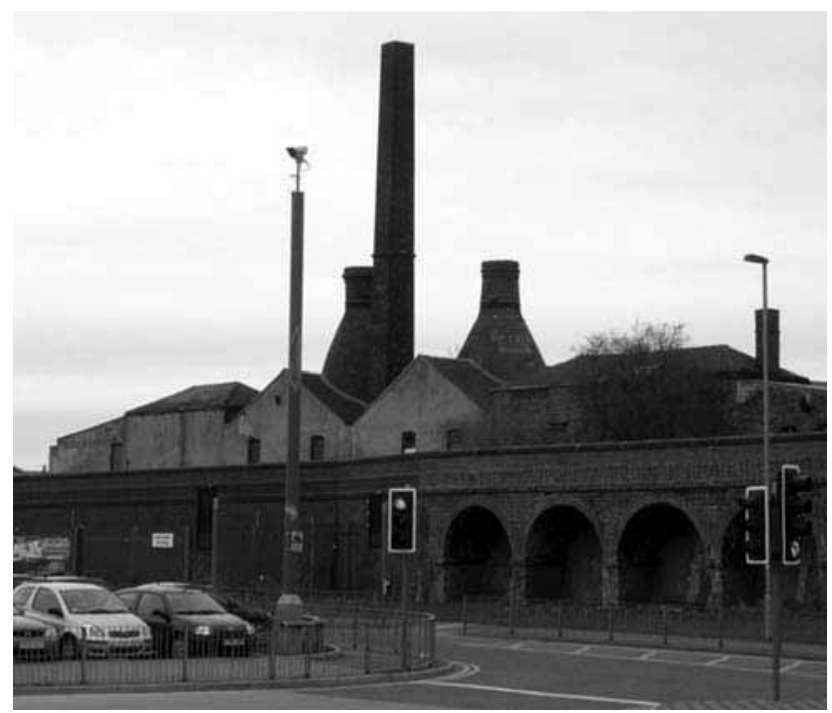

Figure-16: The pot kiln environment of the Potteries from the 1960's; most of the pottery manufacture has now moved abroad.

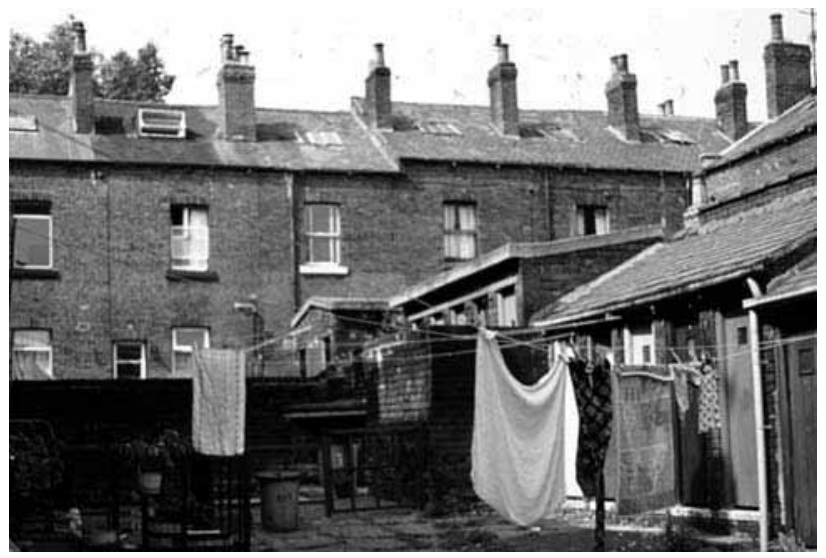

Figure-17: Back-to-back houses, N. Birmingham, 1970's: nobody could claim that such environments deserved saving .... But then along comes the National Trust.

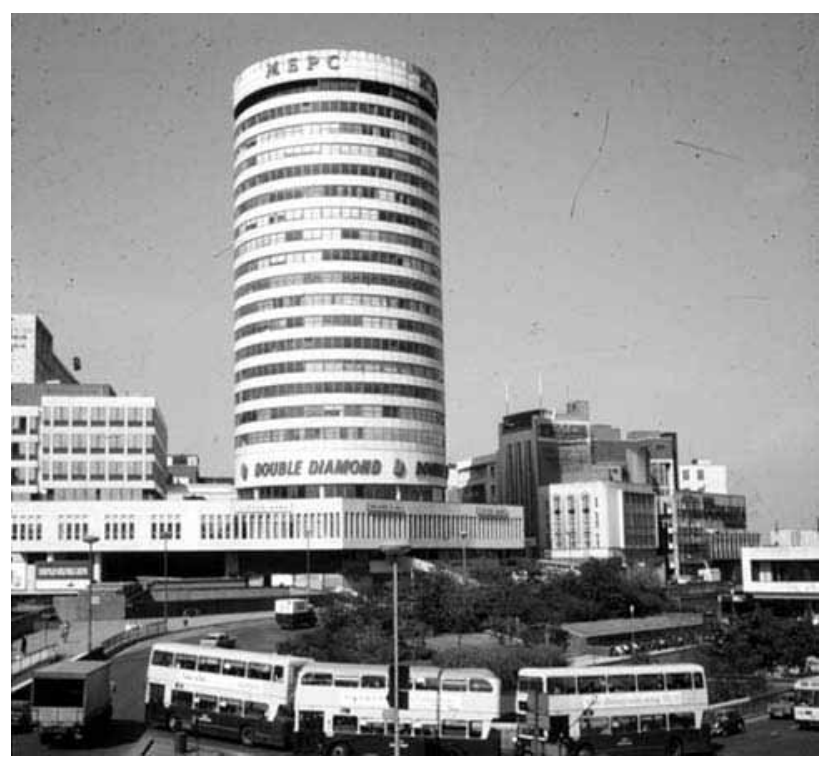

Figure-18: The Rotunda, Birmingham, 1970's. Key feature of a 1960's planning scheme, saved by local memories and now redeveloped.

IRA in the early 1970 's, killing a hundred people, but the building stayed up. The support of Birmingham for this building integrates a memorialization of people with the fact that Birmingham survived. It is the same mentality that survived in the war.

\section{CONCLUSION}

Townscape qualities are only recognized by specialist, affluent, and informed groups. They may actually be local as well, which is even better. But essentially, it is a specialist activity. To sustain the professional belief in conservation of townscapes, one needs to recast the publications and media appearances, and even start producing apps. One 
needs to get the information and ideas into popular language, where people are likely to use them. One needs to develop international evidence that townscape investment benefits all in the development process, and at all scales. Turning a historic building into a cultural center seems like a good thing to do. But ten years later will money still be shoveled into it, is it always on the edge, because it was never going to be profitable - in any terms, not just commercially? One must accept that Lynch's idea - pedestrians navigating the city using landmarks, edges, nodes, districts, and routes does not hold up very accurately in today's fast changing urban scenario. It might have been applicable in the 1960's when his book first came out, but Lynch himself realized ten years later that people experienced cities using wheeled modes of transport more than they did through pedestrianization. It is quite okay, if one has a historic part of the city where one can go have a pleasant walk, or grab a cup of tea, and spend an evening on foot, but it is important to realize that most people today simply do not enjoy cities in that way. Pre-calibrated GPS guides and other modern navigational aids tend to nullify individual townscape expression. People are not going to look at and read buildings when they have a navigation system installed in their cars, and constantly check it to see where they are headed to.

One must find ways of linking to current patterns of experience and design buildings, signs, and electronic prompts according to these. Over concentration on building form and detail has been to the impact of colour (Seo, 2010) and the casual accumulation of sound and smell scapes. Fortunately, at the moment, there are people looking at tiles, and how tiles can be used electronically to give information on buildings. A number of experiments are being conducted throughout the world on how buildings can give information to the passerby. This is where we get to the interesting bit about electronic waves, cities communicating with their

\section{REFERENCES}

Calabi, D., 2004, The market and the city : Square, street and architecture in early modern Europe, Ashgate, Aldershot.

Conn, S., 2010, Do museums still need objects?, University of Pennsylvania Press, Philadelphia.

Fallowell, D. et.al., 2010, 'National trust and disneyfication' (Letter) The Times, 9,X,10.

Goodey, B, Reeve, A. and Shipley, R., 2007, 'Townscape assessment : the development of a practical tool for monitoring and assessing visual quality in the built environment,' Urban Morphology, 11 (1), 25-41.

Goodey, B., 2006, 'Interpreting urban heritage', Issues in Heritage Management: Heritage Interpretation, in Stone, P., Routledge and English Heritage, London, p. 9-31

Goodey,B., Shipley,R., Reeve, S., Walker, S., and Grover, P., 2004, 'Townscape heritage initiatives evaluation : Methodology for assessing the effectiveness of heritage lottery fund projects in the United Kingdom', Environment and Planning $C$ : Government and Policy, 22, 523-42

Goodey, B. and Desimpelaere, W, 2003, 'External evaluation of UNESCO's action in the preservation of cultural heritage damaged by conflict : Bosnia-Herzegovina 1996-2003', UNESCO.

Greiff, C. M., 1974, Lost America : From the Mississippi to the Pacific, The Pyne Press, Princeton.

Lynch, K., 1961, The image of the city, M.I.T. Press, Cambridge.

Lynch, K., 1984, 'Reconsidering the image of the city', in Cities of the mind: Images and themes of the city in the social sciences, in Rodwin, L. and Hollister, R.M., Plenum, New York, p. 131-61

Seo, Yookyung, 2010, 'Colour and place : The role of colour in urban design : Identifying place', Unpublished MA thesis in Urban Design, Joint Centre for Urban Design, Oxford Brookes University.

Shipley, R. and Reeve, A., 2010, 'Evaluating the THI : Measuring the effectiveness of the Townscape Heritage Initiatives', Urban Design International, 15 (Winter), 221-37.

Van Oppen, Renata, 1992, Art on wheels, Ferozsons, Lahore. 
Venturi ,R.,Izenour, S. and Scott Brown. D., 1977, Learning from Las Vegas, The MIT Press, Cambridge.

While, A. and Short, M., 2011, 'Place narratives and heritage management : the Modernist Legacy in Manchester''Area, $43(1), 4-13$

While, A. and Short, M., 2011, 'Place narratives and heritage management: The Maternist legocy in Manchester', Area, 43(1), 4-13.

Wood, L., 1995, 'The conservation and management of historic urban space', International Journal of Heritage Studies, 1 (2), 111-25

Zukin, S., 2010, Naked city : The death and life of authentic urban places, Oxford University Press, New York. 